ARTIGOS

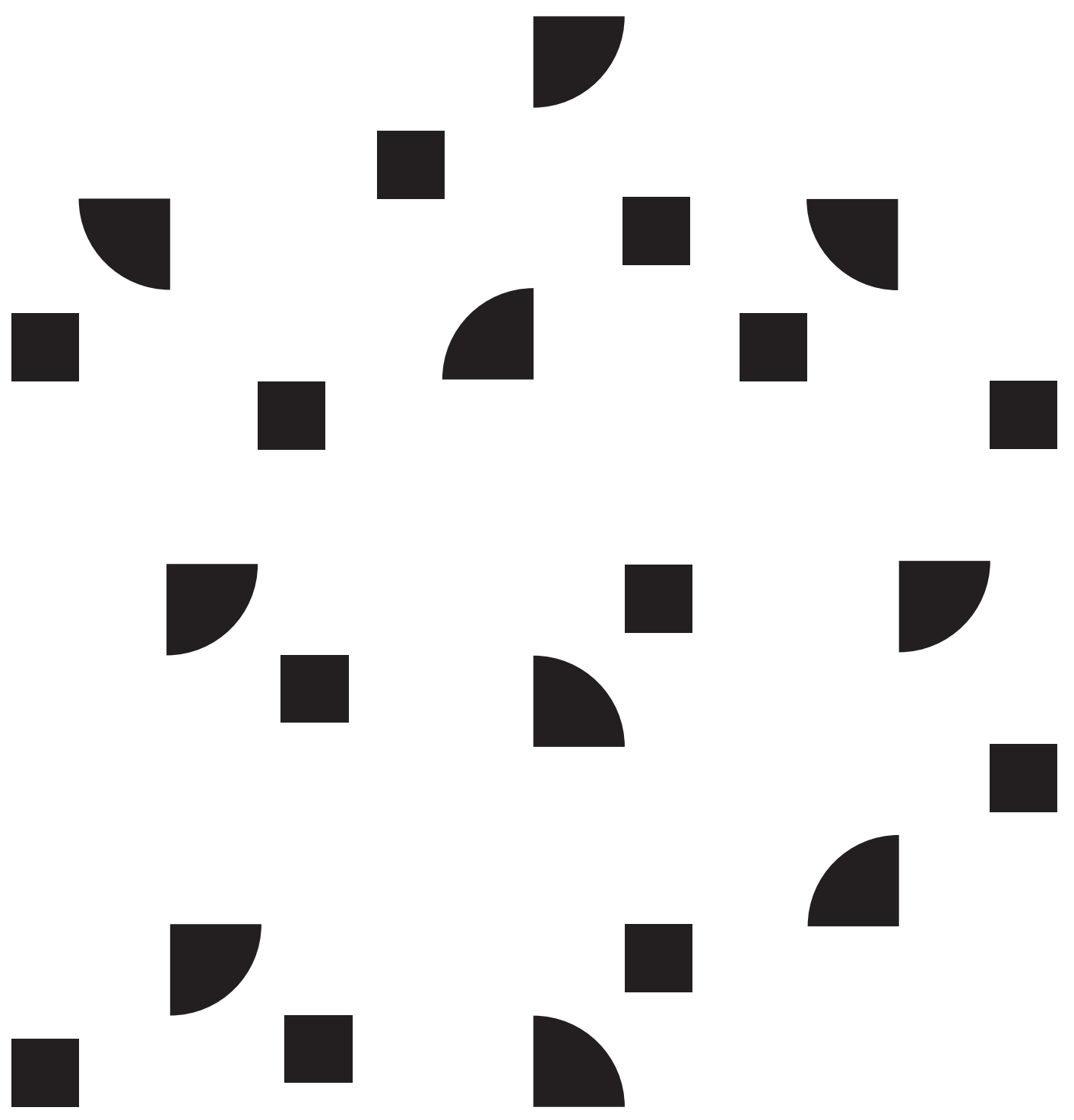




\title{
Experiências de mídia-educação: estudando a fotografia no Ensino Médio ${ }^{1}$
}

\author{
Alexandra Bujokas de Siqueira* , Liana Catarina da Silva Carvalho**
}

\section{Resumo}

Relatam-se resultados de experimento com ensino da leitura crítica de fotografia para alunos do Ensino Médio. As atividades foram elaboradas a partir do conceito internacional de media literacy, que envolve leitura, produção de conteúdo, conhecimento técnico e habilidades para refletir sobre o próprio aprendizado. Foram realizadas quatro oficinas, onde os participantes analisaram imagens dos meios de comunicação, produziram e compartilharam fotos no site Flickr, aprenderam a usar editores de imagens e registraram o aprendizado em blogs individuais. Os resultados sugerem que os estudantes se engajam nas atividades, têm facilidade para aprender procedimentos técnicos necessários à produção de conteúdo, compreendem conceitos relacionados à leitura crítica, mas não conseguem aplicar o conhecimento na vida fora da sala da aula. Eles justificam essa dificuldade pelo fato de não terem oportunidades para se expressar, debater e usar a criatividade no cotidiano da escola. A experiência mostrou que a mídia-educação pode revolucionar práticas escolares desgastadas.

\section{Palavras-chave}

Mídia-educação; media literacy; fotografia; Ensino Médio; leitura crítica.
* Universidade Federal do Triângulo Mineiro (UFTM), Uberaba, MG, Brasil. bujokas@uol.com.br

** Universidade do Sagrado Coração, Bauru, SP, Brasil. lianacarvalho3@yahoo. com.br
1. As autoras agradecem à Fundação de Amparo à Pesquisa do Estado de São Paulo (Fapesp) pelo auxílio à pesquisa e pela bolsa de iniciação científica concedidos para a realização da pesquisa. 


\title{
Experiences in media education: studying photography in high school
}

\begin{abstract}
This paper reports the results of an experiment on critical reading of images for high school students. The activities were designed according to the international concept of media literacy, which involves reading, content production, technical knowledge and skills to reflect on self-learning. Four workshops were held in which participants analyzed photos published in the mainstream media, produced and shared photos on Flickr, learned how to use a cloud computing image editor and reported their learning experience on individual weblogs. The results suggest that students engage with the activities, easily learn technical procedures for media content, understand concepts related to critical reading, but seem not to be able to apply the knowledge in their life outside the workshop room. They justify this difficulty by not having many opportunities to express themselves, to discuss and use creativity in everyday school life. The experience has shown that media education can potentially help to transform worn out pedagogical practices.
\end{abstract}

Keywords Media education; media literacy; photography; secondary school; critical reading. 


\section{Introdução}

Embora o início da educação para a mídia seja tão antigo quanto o próprio surgimento dos meios de comunicação de massa (Halloran; Jones, 1986), foi principalmente, a partir da segunda metade dos anos 1980, que esse assunto passou a ganhar mais espaço na pesquisa acadêmica brasileira, com, por exemplo, a criação de grupos de trabalho na Associação Nacional de Programas de Pós-Graduação em Educação Anped (Vermelho; Areu, 2005) e na Sociedade Brasileira de Estudos Interdisciplinares da Comunicação (Itercom). No âmbito da sociedade civil, entretanto, há relatos de programas de leitura crítica da mídia pelo menos desde os anos 1960, quando a União Cristã Brasileira de Comunicação Social (UCBC) promoveu oficinas de leitura crítica da mídia, em pleno regime militar (Gomes, 1986). Conforme registros da entidade, entre os anos 1970 e 1980, cerca de 40 mil comunicadores populares frequentaram as oficinas do projeto Leitura Crítica da Comunicação (LCC). (Souza; Pereira, 2003).

Nos anos 1990, a interface comunicação e educação se tornou alvo de políticas públicas específicas, tais como o “Proinfo”, a "TV Escola”, a "Rádio Escola”, o "Mídias na Educação" (programas do Ministério da Educação), os "Pontos de Cultura” (do Ministério da Cultura). No âmbito da sociedade civil, são conhecidas, por exemplo, as ações da Agência de Notícias dos Direitos da Infância (Andi), das organizações "Midiativa”, “Jornal Escolar” e "Bem TV”, além da experiência da Escola de Comunicação e Artes da Universidade de São Paulo, com o projeto Educom.rádio e o recentemente criado curso de Licenciatura em Educomunicação.

Em âmbito internacional, a promoção da chamada media literacy - habilidade para acessar, avaliar e produzir conteúdos usando diversas plataformas e linguagens - vem sendo discutida e promovida tanto por governos de países, quanto por organismos multilaterais. Na Inglaterra, desde 2003, o Office of Communications (Ofcom) desenhou e está implementando uma política pública de mídia-educação (Siqueira, 2007). A Inglaterra também lidera o European Charter for Media Literacy, que reúne, além da Grã-Bretanha, entidades da França, da Espanha, da Suécia, da Itália, de Portugal e da Alemanha, num esforço conjunto para promover a mídia-educação na Comunidade Europeia (ECML, 2008).

O departamento de Comunicação e Informação da Unesco, desde 2003, vem trabalhando na criação de referências para a promoção da chamada “Media and Information Literacy", que começou a ser esboçada na Proclamação de Alexandria, em novembro de 2005 (Horton Júnior, 2007). Em 2011, foi lançado o documento Unesco 
media and information literacy curriculum and competency framework for teachers (Referencial curricular e de competências em mídia e informação para professores), que deverá ser testado em programas piloto a ser realizados em oito países, o Brasil entre eles (Unesco, 2008).

Esse breve relato cronológico indica que a mídia-educação é uma especificidade do fazer educativo que vem ganhando consistência e que reúne contribuições de áreas diversas, tais como Ciências da Comunicação, Pedagogia, Sociologia, Linguística, Semiótica, Informática, Design e Cinema. Consequentemente, há uma ampla diversidade de abordagens e objetivos. Entretanto, é muito provável que todas essas iniciativas tragam à tona questões comuns.

Buckingham (2003) destaca algumas questões paradigmáticas neste campo emergente: como identificar o que os estudantes sabem sobre mídia? Como é que eles adquirem compreensão crítica ou de conceitos? Como eles aprendem a usar as mídias para expressar a si mesmos e para se comunicar com os outros? Como eles relacionam o discurso acadêmico com suas próprias experiências, como usuários de mídias? Como podemos identificar e avaliar evidências do aprendizado? Como podemos ter certeza de que a educação para a mídia faz diferença?

Em termos práticos, um desafio importante é saber promover atividades de produção de conteúdo que não sejam, no final das contas, mera celebração da vontade do aluno. Em outras palavras, se o professor não tiver objetivos, metodologia, critérios de avaliação definidos a priori, a produção de vídeos, os programas de rádio, as revistas, os blogs, etc podem ser atividades estimulantes, significativas, divertidas, mas também podem acabar ensinando pouco sobre o papel e o funcionamento dos meios de comunicação. Com efeito, compreender o que é e para que serve a mídia é algo que deve nortear as iniciativas de media literacy.

Esse é o cenário que embasou a criação do projeto Midialab, que reuniu alunos e professores de escola pública de Bauru, São Paulo. O programa foi composto por 20 oficinas, quatro das quais focadas na linguagem fotográfica, objeto do presente trabalho.

0 público-alvo era formado por 20 estudantes do primeiro e do terceiro anos do Ensino Médio de uma escola estadual, situada a três quilômetros do centro da cidade. À época do estudo, o Índice de Desenvolvimento da Educação Básica (IDEB) da escola era de 5,4 pontos, maior do que o índice médio da cidade de Bauru $(4,7)$ e o do estado de São Paulo $(4,3)$. Era também maior que a média nacional para as escolas públicas $(4,9)$, mas inferior ao índice alcançado pelas escolas privadas $(6,4)$. 
Embora a pesquisa não tivesse como objetivo traçar um perfil sociocultural minucioso dos participantes, em conversas informais, durante a realização das atividades, soube-se que os familiares da maioria não haviam frequentado a universidade. Os estudantes eram filhos de caminhoneiros, donos de pequenos estabelecimentos comerciais de bairros, cabeleireiras, taxistas, representantes comerciais, vendedores em lojas de rede, ou alguns tinham mães que eram donas de casa. Menos da metade dos participantes tinha, em casa, computador com acesso à internet, e apenas dois deles afirmavam ter o hábito de ler jornais, geralmente restringindo a leitura à editoria de esportes. Os estilos de música preferidos eram sertanejo e hip hop. Um dos participantes era particularmente interessado em tuning, a prática de equipar carros para competições, e aproveitava o tempo livre para visitar sites relacionados ao tema. Todos eram estudantes do período matutino e tinham entre 15 e 18 anos.

A metodologia consistiu em elaborar planos de trabalho e materiais didáticos que explorassem fundamentos da linguagem e da técnica fotográfica (composição, enquadramento e iluminação) e técnicas de edição jornalística, incluindo redação de legendas, denotação e conotação na fotografia. Esses materiais foram testados nas oficinas e o resultado da experiência foi avaliado de duas formas: a qualidade das produções nos exercícios de leitura e "escrita" com fotografia, a opinião dos estudantes, expressa espontaneamente durante a realização das atividades; e a observação sistemática das gravações em vídeo das atividades.

A seleção de materiais e atividades teve como objetivo encontrar respostas para três das questões paradigmáticas de Buckingham: como é que os estudantes adquirem compreensão crítica ou de conceitos? Como eles aprendem a usar as mídias para expressar a si mesmos e para se comunicar com os outros? Como eles relacionam o discurso acadêmico com suas próprias experiências, como usuários de mídias?

Encontrar respostas para essas perguntas implica saber reunir referências de áreas diversas que, historicamente, vêm contribuindo com as ciências da Educação e da Comunicação. Uma síntese de conceitos pertinentes para o experimento, aqui apresentado, será feita a seguir.

\section{Síntese da fundamentação teórica}

Historicamente, o ensino sobre mídias no Ensino Fundamental e Médio brasileiros tem sido praticado de maneira fragmentada, nas aulas de Português principalmente, de História, Geografia e Artes, em menor escala (Siqueira, 1999). Entretanto, devido 
às inovações tecnológicas e à centralidade das mídias na cultura jovem, tanto a comunidade acadêmica, quanto a escola reivindicam uma abordagem específica e mais sistemática da mídia. 0 número de estudos sobre a interface comunicação e educação cresceu significativamente no Brasil nos últimos 20 anos (Vermelho; Areu, 2005), materiais didáticos específicos são disponibilizados aos educadores, por exemplo, por meio da TV Escola. A experiência indica que duas áreas de estudo e pesquisa são traçadas em nossas universidades: a mídia-educação (ou educação para as mídias), que foca os meios e suas linguagens como "objeto de estudo"; e a comunicação educacional, que foca a apropriação das mídias como ferramentas pedagógicas para apoiar o ensino nas diversas áreas do currículo (Belloni, 2001).

É claro que, na prática educativa, o estudo do conteúdo da mensagem (um vídeo sobre ecologia do Pantanal, por exemplo) e o estudo da mídia vídeo (o modo como os pantaneiros são representados no vídeo) podem ocorrer ao mesmo tempo. Mas pode-se argumentar que os professores têm mais familiaridade com o vídeo como recurso pedagógico do que com a leitura crítica da linguagem e da representação. Daí surge a necessidade de disponibilizar experiências específicas sobre algo relativamente novo para as atuais gerações de educadores: a educação para o uso crítico da mídia. Conforme essa abordagem, o vídeo sobre o Pantanal poderia ser usado na aula de Geografia para estudar um conteúdo específico da área, mas também como um texto midiático que constrói representações específicas, que são resultado de uma rotina de produção e de certos recursos de linguagem.

Como em outras áreas do currículo, não há uma receita da melhor forma de se ensinar sobre mídia, e as abordagens variam conforme a disponibilidade de recursos, o repertório dos professores, o interesse dos alunos e os objetivos previamente definidos. Entretanto, quaisquer que sejam os objetivos e as metodologias, sendo educação escolar, é preciso encontrar formas de avaliar o resultado da ação pedagógica, de maneira coerente com a natureza da atividade educativa que se está praticando no momento.

Se o objetivo maior da mídia-educação é promover a leitura e a apropriação crítica das mensagens, o primeiro passo é investigar como se educa o leitor crítico. Não basta aos alunos terem um conhecimento da ciência: eles precisam desenvolver a autonomia crítica em relação ao uso e ao entendimento da mídia, principalmente quando o professor não está por perto. (Buckingham, 2004).

Para se conquistar a autonomia crítica, Buckingham sugere métodos de análises que não dependam de “leituras corretas”. É preciso entender que leituras de mensa- 
gens midiáticas são moldadas por fatores culturais diversos e que, por isso, variam conforme as características da audiência (Hall, 2003). São, portanto, variadas, e essa variação é que deve ser o ponto de partida para o estudo em sala de aula. Há inclusive, espaço para a manifestação de impressões pessoais, quando professores e alunos podem dividir suas interpretações e sentimentos, assim como refletir e descrever suas experiências diárias com a mídia que ocorrem fora da sala de aula.

Além de dividir e comparar suas respostas, alunos e professores devem analisá-las e refletir sobre as diferenças entre elas: que elementos do texto permitem tais leituras e quais são as consequências de tais leituras para a formação do gosto e das opiniões individuais e coletivas. (Buckingham, 2003).

Nesse sentido, o autor propõe uma abordagem dialógica, na qual são feitas negociações entre o professor e os estudantes, sem impor padrões de certo e errado, mas também sem simplesmente celebrar as experiências e a vontade dos estudantes. Em síntese, o que se propõe é uma abordagem culturalista no estudo dos meios de comunicação na escola. Segundo essa perspectiva, a mídia é o palco das disputas simbólicas, que se materializam no discurso. Saber acessar tais discursos, lê-los, desmontá-los, avaliá-los e remontá-los é o primeiro passo para a promoção da leitura crítica (e autônoma) da mídia.

Pesquisas no campo da mídia-educação (Bevort; Belloni, 2009; Feilitzen; Carlsson, 2002; Moran, 2007) têm mostrado que o estudo das diversas mensagens midiáticas na educação de crianças e jovens é um terreno fértil para o desenvolvimento da leitura crítica e autônoma, porque se trata de uma linguagem presente, influente e familiar a esse público. Como em outros setores da mídia-educação, o estudo da imagem se desenvolve em diversas abordagens e metodologias.

Entretanto, a maioria das propostas tem, na semiologia de Barthes (1990), um ponto de partida, em especial os conceitos de denotação e conotação, ancoragem pelo texto e discurso da fotografia. Trata-se de uma abordagem que pode ser adaptada ao repertório dos estudantes para se explorar os conceitos de linguagem e representação na mídia.

No célebre texto “A mensagem fotográfica”, Barthes parte da leitura de um anúncio de massa de macarrão para desmontar a linguagem da fotografia e identifica ali três mensagens: 1 . a cena literal ou mensagem icônica não codificada; 2 . a cena cultural ou mensagem icônica codificada; 3. a mensagem linguística. A Figura 1 é uma foto retirada de álbum particular, publicada no site Flickr, e exemplifica as três mensagens de Barthes. 


\section{Figura 1 -}

\section{Exemplo de fotografia com as três mensagens de Barthes}

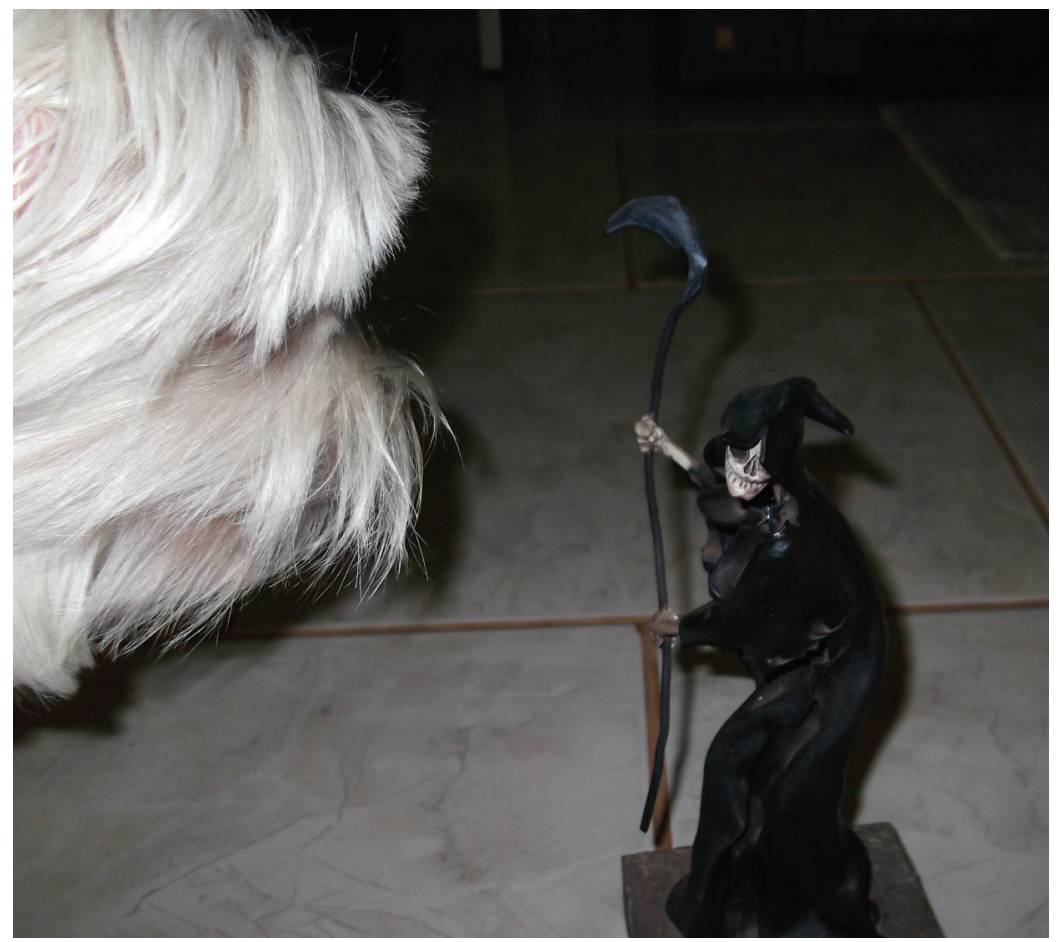

Sid Vicious desafiando a Morte

Fonte: elaborada pelas autoras

Nessa imagem, a cena literal se refere àquilo que estamos vendo objetivamente: um plano fechado, mostrando o focinho de um cão maltês, do lado esquerdo e uma escultura representando a morte, do lado direito. A composição é feita de modo que o cão e a escultura parecem se enfrentar. Ao fundo, veem-se ladrilhos de piso. Entretanto, não é essa leitura objetiva que a maioria das pessoas faz. Ao contrário, essa foto tende a provocar o riso, por causa da irreverência da cena. A identificação dessa irreverência é o que Barthes chama de "cena cultural", produto do confronto entre os signos da imagem e o repertório do leitor. Finalmente, a mensagem linguística se refere a logotipos, slogans e legendas que normalmente acompanham a foto e que servem como uma espécie de âncora, que fixa a imagem em um sentido. A legenda, nesse caso, enfatiza a anedota da cena cultural, ao dizer que o cão está enfrentando a morte. 
Conforme Barthes (1990, p. 67) “É certo que a distinção das duas mensagens icônicas não se faz espontaneamente ao nível da leitura corrente: o espectador da mensagem recebe, ao mesmo tempo, a mensagem perceptiva e a mensagem cultural [...]". A tarefa da mídia-educação é promover essa distinção e explicitar os recursos da linguagem.

Uma proposta de como fazer isso também se fundamenta na obra de Barthes e aplica à fotografia os conceitos de conotação e denotação. Assim, a cena literal deve ser lida como a mensagem denotada, isto é, o conteúdo objetivo da fotografia: planos, composição, objetos, pessoas, gestos. A cena cultural cabe na mensagem conotada e resulta em sentido simbólico ou em representação na fotografia. Barthes identificou seis processos de conotação, sintetizados no Quadro 1.

\section{Quadro 1 -}

\section{Síntese dos processos de conotação, segundo Barthes}

\begin{tabular}{|c|c|c|}
\hline PROCESSO DE CONOTAÇÃO & DEFINIÇÃO & EXEMPLO \\
\hline TRUCAGEM & $\begin{array}{l}\text { No processo de trucagem, o } \\
\text { fotógrafo une artificialmente, } \\
\text { na "segunda realidade", a da } \\
\text { cena congelada, duas imagens } \\
\text { separadas; na "primeira } \\
\text { realidade", o local de onde } \\
\text { a foto foi tirada. É dessa } \\
\text { montagem que surge o sentido. }\end{array}$ & $\begin{array}{l}\text { Uma pessoa passando em } \\
\text { frente a um muro onde há, } \\
\text { desenhado, um tubarão em } \\
\text { posição de ataque. Ao unir } \\
\text { o plano da frente e o plano } \\
\text { do fundo, a imagem sugere } \\
\text { que a pessoa será engolida } \\
\text { pelo tubarão. }\end{array}$ \\
\hline POSE & $\begin{array}{l}\text { No processo de pose, um gesto } \\
\text { espontâneo é fragmentado, } \\
\text { congelado e assume a conotação } \\
\text { de um gesto convencionado. }\end{array}$ & $\begin{array}{l}\text { Uma pessoa de punho cerrado } \\
\text { se movendo para abraçar } \\
\text { outra. Congelada, essa imagem } \\
\text { sugere que uma está prestes a } \\
\text { socar quem, na verdade, } \\
\text { ela vai cumprimentar. }\end{array}$ \\
\hline OBJETOS NA CENA & $\begin{array}{l}\text { Nesse processo, o fotógrafo } \\
\text { valoriza, na composiçãa, os } \\
\text { objetos - artefatos históricos que } \\
\text { têm significados muito precisos --, } \\
\text { estimulando a geraçãa de um } \\
\text { sentido simbólico que, muitas } \\
\text { vezes, anula a realidade de onde } \\
\text { a fotografia foi tirada. }\end{array}$ & $\begin{array}{l}\text { Uma imagem de manifestação } \\
\text { pública de trabalhadores rurais } \\
\text { que, em primeiro plano, fotografe } \\
\text { um deles empunhando uma } \\
\text { foice.. A foice lembra a morte } \\
\text { e também faz parte do símbolo } \\
\text { do comunismo. Num jornal } \\
\text { conservador, essa foto } \\
\text { cria o sentido de morbidez } \\
\text { ou de violência da manifestação, } \\
\text { que poderia ser pacífica. }\end{array}$ \\
\hline
\end{tabular}




\begin{tabular}{|c|c|c|}
\hline PROCESSO DE CONOTAÇÃO & DEFINIÇÃO & EXEMPLO \\
\hline FOTOGENIA & $\begin{array}{l}\text { No processo de fotogenia, o } \\
\text { fotógrafo usa recursos como } \\
\text { enquadramento, composição, } \\
\text { iluminação, velocidade do } \\
\text { obturador. 0 problema é que a } \\
\text { fotogenia pode embelezar coisas } \\
\text { que não são bonitas na realidade. }\end{array}$ & $\begin{array}{l}\text { Artistas de circo em um trapézio, } \\
\text { fotografados de baixo para cima, } \\
\text { em ângulo de } 90 \text { graus, com os } \\
\text { braços muito maiores do que o } \\
\text { resto do corpo, sugerindo sua } \\
\text { força e perícia. }\end{array}$ \\
\hline ESTETICISMO & $\begin{array}{l}\text { No processo de esteticismo, o } \\
\text { fotógrafo usa recursos como cor, } \\
\text { iluminação, textura e, assim, } \\
\text { constrói imagens que lembram } \\
\text { obras de arte. }\end{array}$ & $\begin{array}{l}\text { Imagens de bandeiras, captadas } \\
\text { com baixa velocidade, que } \\
\text { parecem pinturas abstratas, } \\
\text { rostos e corpos fotografados na } \\
\text { contraluz e que lembrem cenas } \\
\text { do pintor Michelangelo Merisi da } \\
\text { Caravaggio. }\end{array}$ \\
\hline SINTAXE & $\begin{array}{l}\text { No processo de sintaxe, o } \\
\text { diagramador aproxima na página } \\
\text { uma determinada sequência de } \\
\text { fotos que, juntas, adquirem um } \\
\text { sentido diferente daquele obtido, } \\
\text { se essas imagens fossem lidas } \\
\text { separadamente. }\end{array}$ & $\begin{array}{l}\text { Foto de uma manifestação } \\
\text { pública, ao lado de uma foto de } \\
\text { um presidente da República, } \\
\text { de perfil, com ar de reprovação. } \\
\text { As fotos podem ter sido tiradas } \\
\text { em épocas diferentes mas, } \\
\text { diagramadas juntas, sugerem que } \\
\text { o governo desaprova o manifesto. }\end{array}$ \\
\hline
\end{tabular}

Fonte: elaborada pelas autoras

Ao separar as três mensagens, analisar os signos, os processos de conotação e a relação entre o texto e a imagem, o estudante aprende a desmontar a linguagem e a identificar o que Tyner (1998) chama de discurso fotográfico. Nesse estágio, a fotografia deixa de ser uma mensagem transparente em relação à realidade e se torna um artefato simbólico na disputa de representações que caracterizam a cultura midiática. Entretanto, ler é uma parte do processo, que só se completa com atividades de produção. Para não simplesmente celebrar a vontade do aluno, uma metodologia educacional precisa ser posta em prática. 0 experimento aqui concretizado será apresentado a seguir.

\section{Desenvolvimento}

As quatro oficinas de fotografia integraram a programação de atividades do Midialab e seguiram a metodologia básica do projeto: ler e produzir conteúdo usando diversas linguagens, a fim de desenvolver habilidades de uso e de análise crítica da mídia. O Quadro 2 sumariza o conteúdo das oficinas. 


\section{Quadro 2 - Resumo do conteúdo das oficinas de fotografia}

\begin{tabular}{|c|c|c|}
\hline OFICINA 1 & $\begin{array}{l}\text { Explorar a linguagem } \\
\text { fotográfica e identificar } \\
\text { o conhecimento prévio dos } \\
\text { alunos sobre essa linguagem. }\end{array}$ & $\begin{array}{l}\text { Fotografar livremente, por meia hora, e trazer as } \\
\text { imagens para conversar sobre elas depois, a partir } \\
\text { das perguntas: o que você quis expressar com essa } \\
\text { imagem? Os colegas interpretam a imagem do mesmo } \\
\text { modo que o autor? Que elementos da fotografia } \\
\text { geram os sentidos atribuídos pelo grupo? }\end{array}$ \\
\hline OFICINA 2 & $\begin{array}{l}\text { Explorar a linguagem } \\
\text { fotográfica e sistematizar } \\
\text { conceitos sobre fotografia. }\end{array}$ & $\begin{array}{l}\text { Adquirir conhecimentos sobre composição } \\
\text { e enquadramento fotográfico, observando } \\
\text { fotos de jornal. } \\
\text { Escolher três imagens do conjunto, feitas na oficina } \\
\text { anterior, e postá-las no blog, analisando-as em } \\
\text { termos de técnicas fotográficas (composição e } \\
\text { enquadramento), legendas possiveis e sentidos que } \\
\text { podem gerar. Completar com uma análise pessoal. }\end{array}$ \\
\hline OFICINA 3 & $\begin{array}{l}\text { Aprender a ler valores } \\
\text { subjacentes à imagem, } \\
\text { usando os conceitos de } \\
\text { denotação e conotação. }\end{array}$ & $\begin{array}{l}\text { Associar palavras a uma imagem do planeta Terra, } \\
\text { feita do espaço. Comparar as palavras próprias com as as } \\
\text { dos colegas. Como explicar a associação da imagem a } \\
\text { valores tão diferentes? } \\
\text { Associar palavras a fotos de esportes diferentes: } \\
\text { ginástica olímpica, basquete, tênis, boxe, etc. Se } \\
\text { todos são esportes, por que valores tão diferentes? } \\
\text { (violência para boxe, elegância para ginástica } \\
\text { olímpica, companheirismo para basquete). } \\
\text { Separar, nas fotografias analisadas, as técnicas } \\
\text { fotográficas que incitaram a associação aos valores } \\
\text { atribuídos pelo grupo. }\end{array}$ \\
\hline OFICINA 4 & $\begin{array}{l}\text { Aprender a gerar, por } \\
\text { meio da técnica fotográfica, } \\
\text { conotações diferentes } \\
\text { para a mesma realidade. }\end{array}$ & $\begin{array}{l}\text { Simular um atropelamento (um aluno deitado } \\
\text { embaixo de um carro, com uma camiseta coberta } \\
\text { de tinta guache vermelha) e fotografar a cena } \\
\text { para meios de comunicação com perfis editoriais } \\
\text { diferentes: jornal diário, jornal sensacionalista e } \\
\text { revista feminina. } \\
\text { Escrever legendas para cada um dos perfis editoriais. }\end{array}$ \\
\hline
\end{tabular}

Fonte: elaborada pelas autoras

A primeira oficina começou com uma conversa informal sobre a relação dos alunos com a fotografia. Foram feitas questões como: vocês gostam de tirar fotos? O que vocês fotografam? Por quê? O que vocês acham das fotos que fazem? Constatou-se que a maioria dos participantes mantinha um perfil atualizado no Orkut, mas não 
conhecia as ferramentas que iríamos utilizar: Flickr e Picnik ${ }^{\mathbf{1}}$. Boa parte do tempo da oficina foi gasto experimentando os recursos dos sites. Ao final da primeira oficina, os alunos saíram pelo campus para fotografar livremente por meia hora, usando duas câmeras digitais tipo cybershot. Ao retornar, eles descarregaram as fotos em dois computadores e analisaram o resultado, em termos de linguagem, atentando para aspectos como foco, ângulo, pose, enquadramento. Uma aluna e um aluno demonstraram, nos seus comentários, ter conhecimentos bastante consistentes sobre linguagem fotográfica, ainda que não soubessem usar termos técnicos mais precisos. O teor dos comentários indicou que eles possuíam um conhecimento difuso e subjetivo, fruto do hábito de fotografar.

A segunda oficina foi dedicada à publicação e à análise das melhores fotos feitas na oficina 1. Os alunos deveriam escolher três fotos, daquelas tiradas no primeiro encontro, postar nas suas contas pessoais no site Flickr, criar um título, definir tags e escrever uma legenda explicando por que haviam escolhido aquela determinada fotografia.

A terceira oficina tinha como objetivo ensinar os alunos a ler os valores subjacentes à imagem, usando os conceitos de denotação e conotação de Barthes. Na primeira parte, foi exibida uma imagem da Terra, tirada do espaço. Os alunos deveriam, ao olhar a imagem, escrever livremente palavras que viessem às suas mentes.

A seguir, eles buscariam identificar quais palavras tinham um sentido mais figurado (conotação) e quais palavras tinham sentido mais literal (denotação). Como eles conheciam o significado desses conceitos aplicados ao texto verbal, não foi difícil transpor a ideia para a imagem. Assim, por exemplo, a palavra "redonda" foi interpretada como denotação, enquanto a palavra "inexplicável” foi interpretada como conotação.

Para reforçar os conceitos de conotação e denotação, foram feitos mais três exercícios. No primeiro, a tarefa era identificar a conotação de dez fotos de esportes. Uma imagem de um time de basquete recebeu conotação de vitória, companheirismo. Isso foi possível porque a foto mostrava a equipe num gesto de celebração. A foto de uma disputa de vale-tudo foi associada a dor, porque mostrava o momento em que um atleta acerta um soco na face do adversário. A foto

2. 0 Flickr é um site especializado na publicação e no compartilhamento de fotografias, que reúne fotógrafos amadores e profissionais. Veja em: www.flickr.com. 0 Picnik é uma ferramenta web 2.0 que permite a edição de fotos usando recursos de computação na nuvem. Veja em: www.picnik.com. de ginástica olímpica foi vinculada a flexibilidade. Ao serem questionados se não havia também dor naquele esporte, eles disseram que sim, mas não era o que viam nas fotos. 
No segundo exercício, foram exibidas imagens de cães retiradas do site Flickr. A tarefa era identificar as representações para cada imagem: cão companheiro (um dálmata brincando com seu dono), animal dócil (um filhote de labrador), símbolo da amizade (um cão e um gato, juntos, olhando para o observador), perigo (um pastor alemão, em um enquadramento de baixo para cima, mostrando os dentes), "libertino vagabundo" (um cão flagrado evacuando na praia, com uma faixa ao fundo, onde se lê "Côco"). À medida que as imagens eram exibidas, os alunos eram estimulados a separar o conteúdo objetivo das fotos e os valores que associavam a cada cena.

Por fim, foram mostrados três anúncios publicitários que tinham em comum a figura da mulher. A questão a ser debatida era: qual deles explora o corpo feminino e por quê?

O primeiro, um anúncio de uísque, trazia uma mulher de biquíni, com metade do rosto cortado e o slogan "Deus é homem". Foi prontamente interpretado como explorando o corpo feminino. Questionados se a exploração estava no fato de a mulher estar de biquíni, uma aluna argumentou que se ela estivesse de biquíni numa propaganda de biquíni, não seria exploração. “Mas mulher de biquíni em propaganda de bebida é diferente", observou.

O segundo anúncio, de um curso de administração a distância, tinha uma foto de uma mulher sentada no chão de uma sala doméstica, com um notebook em cima da mesa. Quando questionados se a peça explorava ou não o corpo, eles disseram que não, porque a mulher estava vestida, sentada, com um comportamento mais "sério".

O terceiro anúncio, de chip de computador, mostrava um atlas do corpo humano, mas, no lugar do desenho tradicional do corpo com os músculos à mostra, havia uma mulher jovem, sorridente, trajando calça jeans justa, de cintura baixa, blusa de alças finas, cabelo solto esvoaçante. De seu corpo, saíam setas indicando os músculos. O slogan do anúncio dizia que estudar com um computador da referida marca era muito mais divertido. Nesse caso, os alunos ficaram em dúvida se havia ou não exploração do corpo, porque a moça estava vestida. Foi-lhes sugerido, então, que pensassem no que a mulher estava representando ali e para quem. Chegou-se à conclusão de que ela significava diversão para estudantes homens, da área de saúde. Poderia ser também exploração do corpo, só que de maneira mais sutil. 
Na quarta e última oficina, foi feita uma atividade de fotografia ligada ao jornalismo. Um atropelamento, utilizando um veículo parado no estacionamento. foi simulado no pátio da escola. Um aluno foi escolhido para ser o modelo. Ele vestiu uma camiseta velha e foi todo manchado de tinta guache vermelha, diluída, para simular o sangue. Antes de fotografar a cena, os alunos estudaram noções de pauta jornalística e linhas editoriais, usando um material produzido especificamente para a atividade. A tarefa era fotografar a cena para três veículos de comunicação com linhas editoriais diferentes: um jornal sensacionalista, uma revista feminina e um jornal diário. Depois da atividade, eles deveriam descarregar as fotos, publicar no Flickr e criar legendas para cada uma delas de acordo com as linhas editoriais dos veículos destinados.

Ao término das quatro oficinas, todo o material produzido foi reunido e somado às gravações das oficinas. Os dados foram então analisados à luz das três perguntas paradigmáticas apresentadas na introdução: como é que os estudantes adquirem compreensão crítica ou de conceitos? Como eles aprendem a usar as mídias para expressar a si mesmos e para se comunicar com os outros? Como eles relacionam o discurso acadêmico com suas próprias experiências, como usuários de mídias?

\section{Resultados e discussão}

Observando o desempenho durante as atividades e os exercícios produzidos pelos alunos, constatou-se que o grupo se engajou tanto na produção quanto na análise, embora os estudantes se mostrassem mais seguros quando falavam e mais reticentes quando escreviam. Todos tiveram facilidade para compreender e para utilizar conhecimentos de caráter técnico, tais como enquadramentos, composição, montagem, uso de ferramentas web 2.0.

Particularmente nas atividades de análise, o grupo demonstrou habilidade para compreender a dubiedade da fotografia, que é análoga ao real mas, ao mesmo tempo, encerra valores simbólicos culturalmente construídos. Tal aprendizado ficou explícito quando foram realizadas as atividades com fotos de esportes, cães e anúncios com fotos de mulher.

De um modo geral, todos produzem conteúdo com desenvoltura, como mostraram os exercícios de captação fotográfica realizados nas oficinas um e quatro. 0 problema surge quando os estudantes são convidados a refletir sistematicamente sobre o que fizeram e por que fizeram daquele jeito. As figuras 2, 3 e 4 exemplificam tal dificuldade. 
Figura 2 - Foto produzida por aluna, durante a primeira oficina, e postada no Flickr

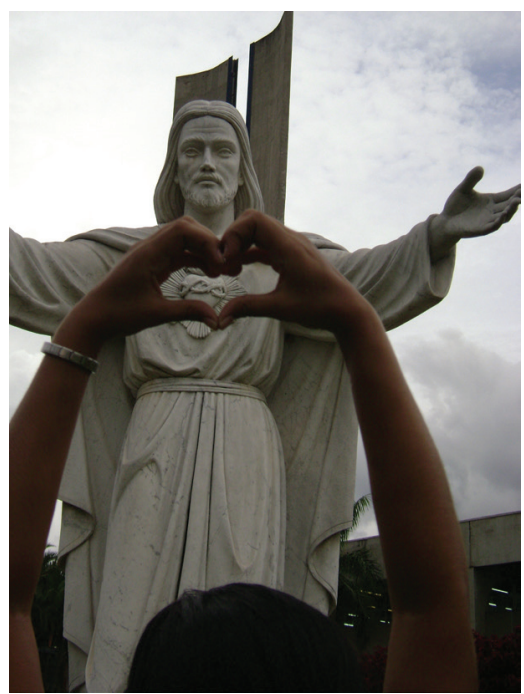

Legenda feita por aluna:

“fiko legal por causa da mao da menina"

Figura 3 - Foto produzida por aluno, durante a primeira oficina, e postada no Flickr

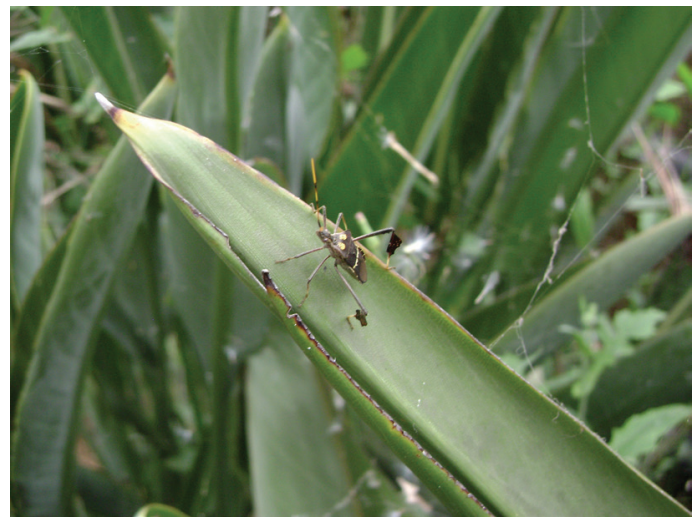

Legenda feita por aluno:

“Pq eu consegui deixar o inseto e a folha em primeiro plano!!!” 


\section{Figura 4 - Foto produzida por aluno, durante a primeira oficina, e postada no Flickr}

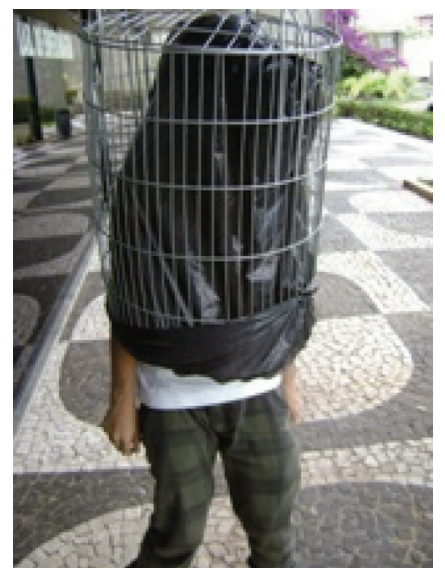

A foto foi publicada sem legenda

Na figura 1, o comentário sugere que a aluna gostou do gesto que imita o coração. É uma foto que confere uma conotação jovem à fé religiosa, mas a aluna não soube falar em gestos, em simpatia, em fé. A análise se ateve à cena literal.

A figura 2 rendeu uma longa conversa. Todos gostaram do resultado, mas não sabiam dizer ao certo o porquê. 0 autor disse ter ficado feliz em registrar o inseto e a folha em primeiro plano. Entretanto, ao fazer perguntas sobre a linguagem e o conteúdo daquela fotografia (Como é a folha? Como é o inseto? Que sentimentos a folha desperta? Que sentimentos o inseto desperta?), percebeu-se que, na verdade, os alunos se impressionaram com o contraste entre um inseto tão pequeno e uma folha tão pontuda e agressiva. Trata-se de uma imagem que fala sobre a fragilidade, mas essa conclusão era implícita, e eles tiveram dificuldade para transformá-la em algo explícito.

A figura 3 foi vista com simpatia por todos. Eles a julgaram divertida. Ao serem questionados se aquela imagem não poderia associar a pessoa ao lixo, eles responderam que sim, mas que não tinham percebido isso. 0 autor da imagem disse que essa ideia jamais lhe passara pela cabeça.

A análise dos resultados sugere, portanto, que a compreensão de conceitos ocorre nos momentos dos exercícios (como na análise dos anúncios publicitários com fotos de mulher). Entretanto, quando são chamados a aplicar o que aprenderam nas suas próprias produções, os estudantes parecem ter mais dificuldade. 
Nas atividades de produção para linhas editoriais diferentes, os alunos tiveram facilidade para se expressar pela linguagem não verbal e mais dificuldade para se expressar por meio do texto. As figuras 5, 6 e 7 sustentam esse ponto de vista.

Figura 5 - Foto produzida por aluno, durante a quarta oficina, para a linha editorial sensacionalista

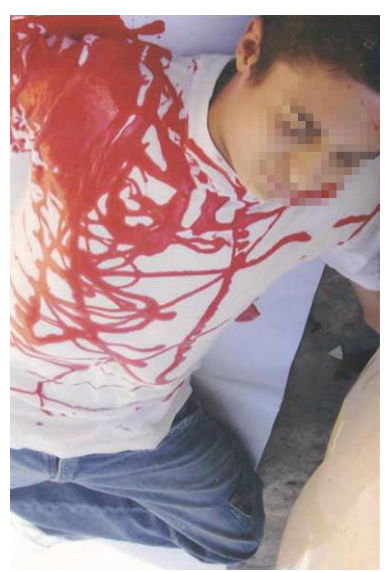

Legenda feita por aluno:

“Jovem morre! Um motorista atropela jovem de 15 anos. Jovem morre na hora"

Figura 6 - Foto produzida por aluno, durante a quarta oficina, para a linha editorial jornal diário

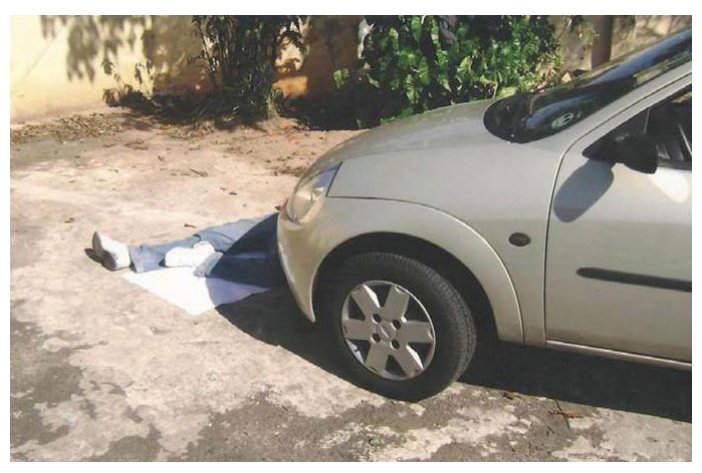

Legenda feita por aluno:

"Muleque morre ao atravessar rua atrás de uma pipa. Motorista foge" 


\section{Figura 7 - Foto produzida por aluno, durante a quarta oficina, para a linha editorial revista feminina}

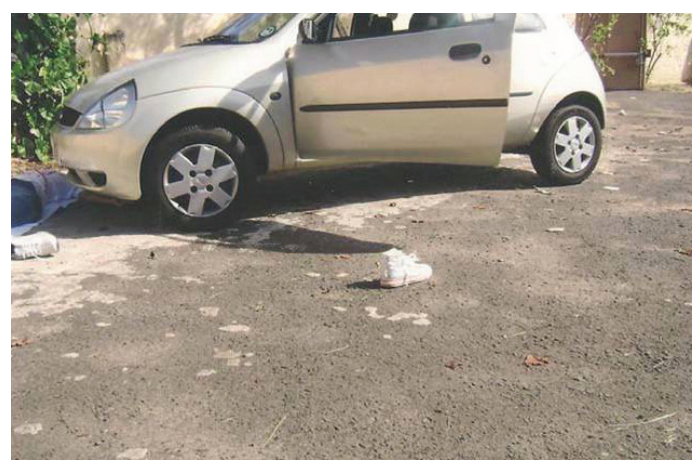

Legenda feita por aluno:

“Jovem morre após acidente. Condutora deixa o local do crime e deixa seu tênis para trás”

Ao retratar a cena, os autores souberam escolher planos e composição que evidenciassem aspectos específicos - sangue, cenário do crime e a trivialidade do tênis deixado durante a fuga. As legendas, entretanto, não diferem na linguagem: o viés sensacionalista usa pontos de exclamação mas não faz o apelo dramático necessário. O que se esperava dessa legenda era algo como: “Jovem atropelado sangra até morrer”. Em outras palavras, não há correspondência entre os aspectos enfatizados na imagem e no texto, e essa era a tarefa para a atividade.

A foto para jornal diário evitou o sensacionalismo no plano da imagem, mas a legenda não foi formal o suficiente para essa linha editorial. A imagem e a legenda produzidas para a revista feminina foram as que mais se aproximaram do objetivo, talvez por terem sido feitas por alunas mulheres, que têm mais familiaridade com esse estilo de texto e imagem.

Os registros em vídeo e da opinião dos estudantes captaram as razões para a dificuldade com o texto verbal. Segundo eles, nas atividades diárias da escola, há pouco espaço para a criatividade e, na maioria das vezes, eles são avaliados pela capacidade de usar a norma, mas não pela capacidade de expressão ${ }^{2}$. Conse-

3. Por causa desse registro, nas atividades com texto, optamos por não corrigir erros de gramática e ortografia e por não interferir no "internetês". quentemente, os alunos se sentem diminuídos e não têm segurança para escrever, como mostra a transcrição dos diálogos: 
Pergunta: Por que vocês não conseguiram explicar direito o que sabem?

Aluna 3: Tenho medo de errar. Eu acho que foi isso. Porque você explicou tudo, mas foi chegando no dia de fazer eu esqueci tudo.

Pergunta: Vocês se sentiram presos de alguma forma para poder escrever? Com medo de alguma coisa?

Aluna 3: De escrever alguma palavra errada. Eu fiquei com vergonha porque vocês iam rir e falar: "olha o jeito que ela tá escrevendo". Por causa disso.

Pergunta: Vocês acham que é dificil escrever o que vocês viram? É mais fácil falar?

Todos: É mais fácil falar.

Pergunta: Vocês ficaram inseguros porque a gente ia ler depois?

Todos: Sim.

Aluna 3: Eu acho que foi a forma de eu escrever, eu fiquei com vergonha. Já pensou: "ai ela tá no primeiro colegial e tá escrevendo essas palavras erradas?" Porque se fosse pra falar, eu ia falar um monte das imagens.

Pergunta: Você ficou com medo da própria escrita?

Aluna 3: $E$.

Por fim, alguns depoimentos espontâneos sugeriram que os alunos, nas suas relações diárias com as mídias, tiveram mais facilidade para relacionar aspectos técnicos do que para interpretar o sentido. Eles relataram, por exemplo, as análises que passaram a fazer das fotos do livro de História: como eram antigas, não tinham os recursos de composição e o enquadramento que estavam sendo estudados. Em outra ocasião, os alunos foram fotografados por uma repórter do jornal local e disseram ter dado sugestões sobre como enquadrar a imagem, o que, segundo eles, rendeu uma boa conversa com a jornalista.

Os resultados indicam, portanto, que os alunos se engajam nas atividades e, no momento em que elas estão sendo realizadas, parecem ter desenvoltura para compreender conceitos e para analisar criticamente as mensagens midiáticas, embora esse seja um conhecimento implícito e difícil de ser explicitado pela linguagem falada e, principalmente, pela escrita. Eles também demonstram muita desenvoltura e entusiasmo para aprender procedimentos técnicos necessários à produção de conteúdo midiático, mas não conseguem explicar para os outros as suas intenções. 0 aprendizado crítico parece fluir durante as oficinas, mas nem sempre alcança a vida fora da 
sala da aula; o que não acontece com as questões de caráter técnico, como mostraram os depoimentos sobre as fotos do livro de História e o episódio com a jornalista.

\section{Considerações finais}

Os experimentos realizados no Midialab indicam que a mídia-educação é um campo multidisciplinar privilegiado para oferecer aos estudantes oportunidades para se expressar, usar a criatividade, experimentar com diversas linguagens, refletir sobre a própria aprendizagem. Entretanto, o objetivo fundamental da mídia-educação, de formar leitores-produtores críticos e autônomos, é barrado por uma questão anterior e maior: há uma dificuldade intrínseca em conseguir fazer com que os alunos explicitem o conhecimento que têm ou que vão adquirindo, seja para os outros, seja para eles próprios. Sem essa habilidade, a proposta da mídia-educação não tem como ser realizada em todo o seu potencial.

Assim, ao concluir o experimento, algumas novas questões vieram à tona: como ensinar esses jovens a refletir sobre os próprios gostos e crenças no tocante à cultura de massa? Como superar as dificuldades relativas à expressão de ideias e à reflexão sistemática?

Conforme declarações dos próprios alunos, se os professores não refletem sobre seus conhecimentos e não promovem a reflexão na sala de aula, consequentemente, os estudantes também não vão conseguir fazê-lo. Eles reclamaram que as aulas são muito "automáticas" e que eles não têm espaço para usar a própria criatividade; eles têm ideias, mas ficam intimidados em expressá-las.

Em termos práticos, a conclusão da experiência mostrou que a mídia-educação, potencialmente, pode revolucionar práticas escolares desgastadas. 0 próximo passo é sedimentar o estudo da mídia na formação de professores, incluir formalmente esse conhecimento como componente curricular e criar materiais pedagógicos próprios. 


\section{Referências bibliográficas}

BARTHES, R. O óbvio e o obtuso: ensaios sobre fotografia, cinema, pintura, teatro e música. Rio de Janeiro: Ed. Nova Fronteira, 1990.

BELLONI, M. L. O que é mídia-educação. Campinas, SP: Autores Associados, 2001. (Coleção polêmicas do nosso tempo; 78).

BEVORT,E.;BELLONI,M.L.Mídia-educação:conceitos, históriaeperspectivas. Educação \& Sociedade, Campinas, v. 30, n. 109, p. 1081-1102, set./dez.2009. Disponível em: 〈http://dx.doi.org/10.1590/S0101-73302009000400008〉. Acesso em: 21 nov. 2012. BUCKINGHAM, D. Cultural studies goes to school: reading and teaching popular media. 2. ed. Londres: Taylor and Francis, 2004.

BUCKINGHAM, D. Media education: literacy, learning and contemporary culture. Cambridge: Polity Press, 2003.

EUROPEAN CONFERENCE ON MACHINE LEARNING - ECML. Carta europeia para uma literacia dos media. Disponível em: 〈http://www.euromedialiteracy.eu/index. php?Pg=charter\&id=4〉. Acesso em: 16 abr. 2008.

FEILITZEN, C. V.; CARLSSON, U. (Org.). A criança e a mídia: imagem, educação, participação. Brasília: Unesco; São Paulo: Cortez, 2002.

GOMES, P. G. O projeto de leitura crítica da comunicação da UCBC. In: KUNSH, M. M. K. Comunicação e educação: caminhos cruzados. São Paulo: Loyola, 1986.

HALL, S. Da diáspora. Belo Horizonte: Editora UFMG, 2003.

HALLORAN, J. D.; JONES, M. Learning about media: communications and society. Paris: Unesco, 1986. (Unesco papers).

HORTON JUNIOR, F. W. Understanding information literacy: a primer. Paris: Unesco, 2007.

MORAN, J. M. Desafios na comunicação pessoal. 3. ed. São Paulo: Paulinas, 2007.

PEREIRA, S. C. Mídia-educação no contexto escolar: mapeamento crítico dos trabalhos realizados nas escolas de ensino fundamental em Florianópolis. In: REUNIÃO ANUAL DA ANPED, 31., 2008, Caxambu. Anais... Caxambu, 2008. p. 1-16.

SIQUEIRA, A. B. Educação para a mídia como política pública: experiência britânica e referências para o Brasil. Comunicação \& Política, Rio de Janeiro, v. 25, p. 73-100, 2007. 
SIQUEIRA, A. B. O jornal e a educação: leitura crítica, comunicação e criatividade no Ensino Fundamental. 1999. 235 f. Dissertação (Mestrado em Educação)-Faculdade de Filosofia e Ciências, Universidade Estadual Paulista “Júlio de Mesquita Filho”, Marília, 1999.

SOUZA, H. R. ; PEREIRA, J. A. C. Da academia para as comunidades: mudança de perfil do trabalho da UCBC na gestão Pedro Gilberto Gomes. PCLA. Revista Científica Digital, São Paulo, v. 4, n. 4, jul./ago./set. 2003. Disponível em: 〈http://www2.metodista.br/ unesco/PCLA/revista16/perfis\%2016-1.htm.> Acesso em: 21 nov. 2012.

TYNER, K. Literacy in a digital world. Mahwa: Lawrence Erlbaum, 1998.

UNESCO. Teacher training curricula for media and information literacy - Report of the international expert group meeting UNESCO house. Paris:Unesco. 2008.

VERMELHO, S. C.; AREU, G. I. P. Estado da arte da área de educação \& comunicação em periódicos brasileiros. Educação e Sociedade, Campinas, v. 26, n. 93, 2005.

Submetido à publicação em 19 de abril de 2012.

Aprovado em 25 de fevereiro de 2013. 